\title{
Preparation and antioxidant properties of selenium nanoparticles-loaded chitosan microspheres
}

\author{
This article was published in the following Dove Press journal: \\ International Journal of Nanomedicine \\ 21 June 2017 \\ Number of times this article has been viewed
}

\section{Kaikai Bai ${ }^{1,2}$ \\ Bihong Hong',2 \\ Jianlin $\mathrm{He}^{1,2}$ \\ Zhuan Hong ${ }^{1,2}$ \\ Ran Tan ${ }^{1,2}$}

'Third Institute of Oceanography, ${ }^{2}$ Engineering Research Center of Marine Biological Resource, Comprehensive Utilization, State Oceanic Administration, Xiamen, People's Republic of China
Correspondence: Kaikai Bai Third Institute of Oceanography, State Oceanic Administration, No 184, Daxue Road, Siming District, Xiamen, Fujian 361005, People's Republic of China Email kkbai@tio.org.cn

\begin{abstract}
Selenium nanoparticles (SeNPs), as a special form of selenium (Se) supplement, have attracted worldwide attention due to their favorable properties and unique bioactivities. Herein, an eco-friendly and economic way to prepare stable SeNPs is introduced. SeNPs were synthesized in aqueous chitosan (CTS) and then embedded into CTS microspheres by spray-drying, forming selenium nanoparticles-loaded chitosan microspheres (SeNPs-M). The physicochemical properties including morphology, elemental state, size distribution and surface potential were investigated. Institute of Cancer Research mice were used as model animal to evaluate the bioactivities of SeNPs-M. Trigonal-phase SeNPs of $\sim 35 \mathrm{~nm}$ were synthesized, and SeNPs-M physically embedding those SeNPs were successfully prepared. Amazingly, acute toxicity test indicated that SeNPs-M were much safer than selenite in terms of Se dose, with a $\mathrm{LD}_{50}$ of around 18-fold of that of selenite. In addition, SeNPs-M possessed powerful antioxidant activities, as evidenced by a dramatic increase of both Se retention and the levels of glutathione peroxidase, superoxide dismutase and catalase. The design of SeNPs-M can offer a new way for further development of SeNPs with a higher efficacy and better biosafety. Thus, SeNPs-M may be a potential candidate for further evaluation as an Se supplement with antioxidant properties and be used against Se deficiency in animals and human beings.
\end{abstract}

Keywords: selenium, nano, microsphere, chitosan, antioxidant

\section{Introduction}

As a dietary nutrient, Se is an indispensable trace element required for most of the living organisms including animals and human beings. ${ }^{1}$ Se is present in at least 25 human selenoproteins and enzymes as selenocysteine, which plays an essential role in preventing various diseases such as cardiovascular disease, hypercholesterolemia and certain cancers. ${ }^{1,2}$ To meet the daily requirement of Se, extra Se supplementation is necessary, especially for those having Se deficiency. ${ }^{1,2}$ Some Se compounds in both inorganic and organic forms, such as selenite, selenomethionine and Se-methylselenocysteine, have been used for decades to avoid Se deficiency in animals and human beings. ${ }^{2}$ However, these Se supplements, especially the inorganic ones, are usually toxic when taken above their nutritional dosage. ${ }^{2}$

In the recent years, SeNP, a kind of elemental Se particle at a nano-size scale with a bright red color, has aroused worldwide attention due to its unique properties and excellent biological activities. ${ }^{2-5}$ It not only scavenges the free radicals in vitro ${ }^{6}$ but also improves growth, serum oxidant status and Se concentration in vivo. ${ }^{3-5}$ Amazingly, compared with Se compounds such as selenite, ${ }^{3,5}$ selenomethionine, ${ }^{4}$ Se-yeast ${ }^{5}$ and Se-methylselenocysteine, ${ }^{7}$ SeNPs exhibit much lower acute toxicity while increasing 
the activities of selenoenzymes. ${ }^{2-5}$ Besides, SeNPs are able to inhibit the growth of microorganisms. ${ }^{8}$ They also exhibit antitumor activities both in vitro ${ }^{9,10}$ and in vivo, ${ }^{11}$ by inducing mitochondria-mediated apoptosis ${ }^{9}$ and stimulating immune reaction against cancer cells. ${ }^{11}$ Thus, SeNPs are considered as a prospective Se formulation for nutritional supplement use, chemoprevention and chemical therapy against cancer.

However, the application of SeNPs is limited by the following facts: (1) economic and environment-friendly ways to synthesize SeNPs are needed ${ }^{10,12-14}$ and (2) bare SeNPs usually enlarge, aggregate and finally transform into a gray/black analog that is thermodynamically stable, but biologically inert. ${ }^{15,16}$ Actually, even an increase in the size of SeNPs can lead to significant reduction in the activities of these nanoparticles such as scavenging multiple radical species in vitro ${ }^{6}$ and enhancing Se accumulation and GSH S-transferase activity in vivo. ${ }^{17}$ It has also been proved that SeNPs are most effective as a chemopreventive agent at a smaller particle size. ${ }^{17}$ Thus, it seems that only SeNPs with a smaller size can guarantee high bioactivities.

Over the past decade, much effort had been devoted to synthesize and stabilize SeNPs with the use of polysaccharides, ${ }^{15,18-20}$ monosaccharides, ${ }^{21}$ proteins, ${ }^{3,22-24}$ amino acids, ${ }^{25}$ polyphenols, ${ }^{26-28}$ melatonin, ${ }^{29}$ ATP,${ }^{30}$ complex plant extract ${ }^{10,31}$ and even microorganism culture. ${ }^{8}$ Among them, polysaccharide is regarded as an appropriate template for fabricating SeNPs when considering energy efficiency and eco-friendliness, according to Zhang et al. ${ }^{15}$ However, the SeNPs prepared using polysaccharides were found to be unstable, due to enlargement of size and decrease of zeta potential during storage in aqueous environment. ${ }^{15,19}$ Moreover, SeNPs preserved using aqueous polysaccharide often encounter and form aggregates. Hence, an improved method of synthesizing SeNPs is needed.

CTS is the only positively charged natural polysaccharide, having excellent biodegradable and biocompatible characteristics. ${ }^{32}$ It has been extensively examined in the pharmaceutical industry for its potential in the development of medicine delivery systems. ${ }^{32}$ Herein, a novel form of SeNPs, named SeNPs-M, was designed and manufactured by two steps: (1) SeNPs were synthesized in the presence of CTS, and (2) the resultant CTS-SeNPs were embedded into CTS microspheres by spray-drying method to form SeNPs-M. Each SeNP was physically separated and preserved into solid SeNPs-M. Besides, the physical and chemical characteristics of SeNPs-M were investigated for a deeper understanding of the bioactivities of SeNPs-M to evaluate the application of SeNPs in this from.

\section{Materials and methods Reagents and animals}

CTS (90.32\% deacetylated, average molecular weight of $37 \mathrm{kDa}$ ) of food grade was purchased from Aoxin Pharmaceutical Co. Ltd (Taizhou, People's Republic of China). The assay kits for measuring TBARS, GSH, CAT, SOD, GSH-Px and protein were provided by Jiancheng Bio-engineering Institute (Nanjing, People's Republic of China). Acetic acid, sodium selenite, Vc and other reagents of analytical reagent-grade quality were obtained from Sigma-Aldrich (Shanghai) Trading Co. Ltd (Shanghai, People's Republic of China).

ICR mice of specific-pathogen-free grade, 4-5 weeks old, 18-22 g bw, were supplied by Xiamen University Animals Laboratory Center (Xiamen, People's Republic of China) with the license no SCXK 2013-0001. The procedures used in animal experiments were approved by the Animal Ethics Committee of Xiamen University, and were also compliant with the Provisions and General Recommendation of Chinese Experimental Animals Administration Legislation.

\section{Synthesis of SeNPs and SeNPs-M}

SeNPs were synthesized by reducing selenite as described by Zhang et $\mathrm{al}^{15}$ with small modification. In brief, $0.5 \mathrm{~g}$ of CTS and $1.6 \mathrm{~g}$ of Vc were dissolved in $100 \mathrm{~mL}$ of $1 \%(\mathrm{w} / \mathrm{w})$ acetic acid. Then, $10 \mathrm{~mL}$ of selenite aqueous solution containing $0.4 \mathrm{~g}$ of sodium selenite was slowly added to the CTS/Vc solution and vigorously stirred (600-800 rpm) to obtain a CTS-SeNPs colloid (shown in Scheme 1A). The SeNPs could be stable at $25^{\circ} \mathrm{C}$ for at least 4 weeks, without any visible precipitation. Bare SeNPs were gained by replacing CTS with deionized water during the preparation of CTS-SeNPs.

Consequently, the CTS-SeNPs colloid was dialyzed against $1 \%(\mathrm{w} / \mathrm{w})$ acetic acid for 6 hours to remove the excess Vc and other by-products. After that, the colloid was well mixed with another CTS solution, with the final concentrations of Se and CTS being $0.09 \%(\mathrm{w} / \mathrm{w})$ and $2.5 \%(\mathrm{w} / \mathrm{w})$, respectively. The spray-drying process was applied to evaporate the moisture of the new mixture (shown in Scheme 1A). ${ }^{33}$ A laboratory spray dryer (SY-6000; Shiyuan Biological Equipment Engineering Co. Ltd., Shanghai, People's Republic of China) with a standard $0.7 \mathrm{~mm}$ nozzle was used under the working condition: inlet temperature $160^{\circ} \mathrm{C}$, pumping flow rate $500 \mathrm{~mL} /$ hour, spray air pressure $0.35 \mathrm{~kg} / \mathrm{cm}^{2}$ and drying air flow discharge $600 \mathrm{~m}^{3}$ /hour. Thus, SeNPs-M were generated with the expected structure shown in Scheme 1B. The Blank-M without any SeNP was prepared by replacing selenite with deionized water. The Se content of each sample was determined by ICP-MS assay according to Dufailly et al. ${ }^{34}$ 

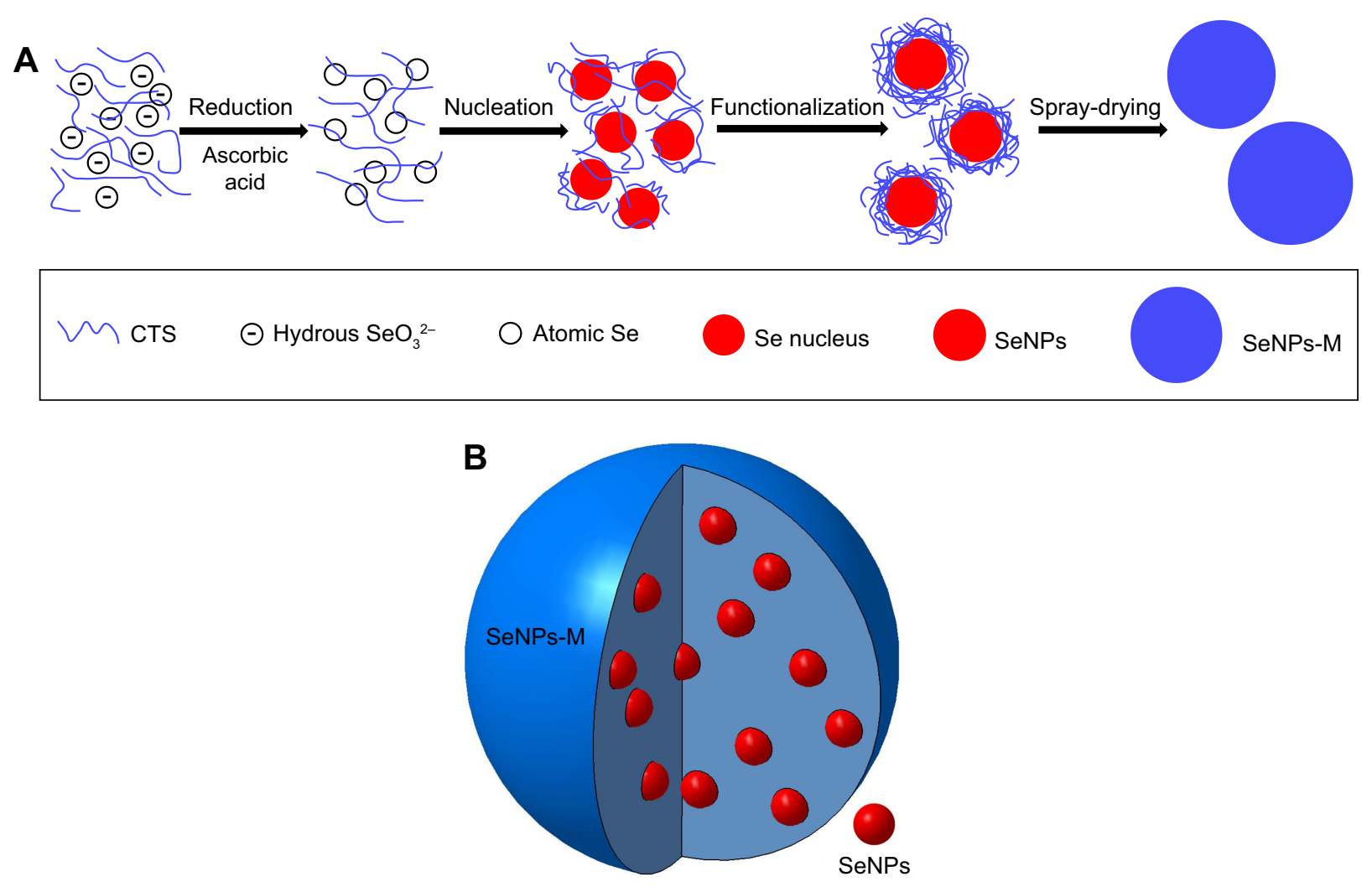

Scheme I The preparation process (A) and the expected structure (B) of SeNPs-M. In brief, CTS and Vc were dissolved in acetic acid solution. Consequently, aqueous sodium selenite was slowly added to the CTS/Vc solution, resulting in atomic Se. Atomic Se nucleated to form Se nucleus, and the Se nucleus assembled into SeNPs. The mixture of aqueous CTS and SeNPs was spray-dried to obtain spherical SeNPs-M.

Abbreviations: Se, selenium; SeNPs-M, selenium nanoparticles-loaded chitosan microspheres; CTS, chitosan; Vc, ascorbic acid; SeNPs, selenium nanoparticles.

\section{Morphology observation and EDS}

TEM (JEM-2100; JEOL, Tokyo, Japan) was applied to study the morphological characteristics of SeNPs. Briefly, diluted SeNPs solution was dropped onto copper grids and dried in clean air. TEM observation was carried out at an accelerating voltage of $200 \mathrm{kV}$. Additionally, the details of microspheres were observed by SEM (S-4800; Hitachi, Tokyo, Japan). The microspheres were coated with platinum in a vacuum state, and the photographs were taken at an accelerating voltage of $2-10 \mathrm{kV}$. In particular, samples were frozen at $-30^{\circ} \mathrm{C}$ and then cut into frozen sections by a Microtome Cryostat (CM1850; Leica, Wetzlar, Germany), each $6 \mu \mathrm{m}$ thick. The frozen sections were observed by SEM. Meanwhile, EDS was applied during TEM and SEM.

\section{FTIR}

Each sample was dried and then ground into a homogeneous powder with potassium bromide to record the infrared spectra on a Nicolet Nexus 470 spectrometer (Thermo Fisher Scientific, Waltham, MA, USA). The spectra were acquired at $400-4,000 \mathrm{~cm}^{-1}$ wavenumbers with a $4 \mathrm{~cm}^{-1}$ resolution.

\section{XPS}

XPS measurement was conducted by a high-resolution photoelectron spectrograph (Escalab 250Xi; Thermo Fisher Scientific) which was equipped with a monochromatic Al $\mathrm{K} \alpha \mathrm{X}$-ray source featuring a highly focused beam size of $500 \times 500 \mu \mathrm{m}$. The energy resolution was $0.05 \mathrm{eV}$. A dualbeam charge neutralization system composed of a low-energy electron flood gun $(\sim 1 \mathrm{eV})$ and an Argon ion gun $(\leq 10 \mathrm{eV})$ was used.

\section{XRD}

The XRD patterns were recorded with an X-ray diffractometer (X'Pert Pro MPD system; Philips, Amsterdam, the Netherlands), using a $\mathrm{Cu} \mathrm{K} \alpha$ source ( $\lambda=0.15406 \mathrm{~nm}$ ). Besides, crystallographic identification was accomplished by comparing the experimental XRD patterns with those of Joint Committee on Powder Diffraction Standards (JCPDS) database. ${ }^{13}$

\section{Measurement of particle size and surface charge}

Hydrodynamic sizes and zeta potentials of nanoparticles were measured using a Zetasizer Nano ZS particle analyzer (VEM3600; Malvern Instruments, Malvern, UK) with a $173^{\circ}$ 
Table I Acute lethal effects of selenite and SeNPs-M after single oral administration in ICR mice $(n=10)$

\begin{tabular}{|c|c|c|c|c|c|}
\hline \multicolumn{3}{|l|}{ Sodium selenite } & \multicolumn{3}{|l|}{ SeNPs-M } \\
\hline Se dose $(\mathrm{mg} / \mathrm{kg} \mathrm{bw})^{\mathrm{a}}$ & Mouse mortality (\%) & $\mathrm{LD}_{50}{ }^{\mathrm{b}}(\mathrm{mg} \mathrm{Se} / \mathrm{kg} \mathrm{bw})$ & Se dose $(\mathrm{mg} / \mathrm{kg} \mathrm{bw})^{a}$ & Mouse mortality (\%) & $\mathrm{LD}_{50}{ }^{\mathrm{b}}$ (mg Se/kg bw) \\
\hline 11.0 & 100 & $3.4(2.4-4.7)^{c}$ & 145.9 & 100 & $62.3(44.7-67.1)^{c}$ \\
\hline 5.9 & 70 & & 82.0 & 50 & \\
\hline 3.2 & 50 & & 46.1 & 30 & \\
\hline 1.7 & 20 & & 26.0 & 20 & \\
\hline 0.9 & 0 & & 14.6 & 0 & \\
\hline
\end{tabular}

Notes: ${ }^{a} \mathrm{mg} / \mathrm{kg}$ bw means $\mathrm{mg}$ Se per kilogram of body weight. ${ }^{b} \mathrm{LD}_{50}$ refers to median lethal dose. ${ }^{\mathrm{T}}$ The number in brackets represents $L D_{50}$ of $95 \%$ confidence interval.

Abbreviations: ICR, Institute of Cancer Research; Se, selenium; SeNPs-M, selenium nanoparticles-loaded chitosan microspheres; bw, body weight.

scattering angle according to Kong et al. ${ }^{19}$ The measurements based on DLS theory were performed under the following conditions: particle refractive index 1.590, particle absorption coefficient 0.01 , dispersant (water) refractive index 1.33 and temperature $25^{\circ} \mathrm{C}$. In addition, another particulate size analyzer (LS-POP(6); Zhuhai OMIC Instruments Co. Ltd., Zhuhai, People's Republic of China) was utilized to determine the size distribution of microspheres, with a particle reflective index of 1.70 and fluid reflective index of 1.33 .

\section{Animal experiments}

ICR mice were used to evaluate the bioactivities of samples in two experiments. In each experiment, mice were housed in plastic cages (only one gender each) in a room with controlled temperature $\left(25^{\circ} \mathrm{C} \pm 2^{\circ} \mathrm{C}\right)$ and humidity $(50 \pm 10 \%)$ and a 12-hour light/dark cycle. After the oral administration of candidate samples, mice were allowed free access to low-Se $\operatorname{diet}(<0.1 \mathrm{mg} \mathrm{Se} / \mathrm{Kg}$ diet $)$ and water.

For the first experiment, the acute lethal properties of sodium selenite, Blank-M and SeNPs-M were measured. After adaption for 3 days, 110 ICR mice were randomly divided into 11 groups with 10 mice per group. Among them, one group was orally administrated saline as control, while the other groups were intragastrically administered sodium selenite or SeNPs-M as shown in Table 1. Cumulative mortality within 14 days after the treatment was recorded to calculate median lethal dose (or $\mathrm{LD}_{50}$ ) by Bliss method. ${ }^{35}$ Besides, another group of 20 ICR mice was given Blank-M at an accumulated dose of $15 \mathrm{~g} / \mathrm{kg}$ bw within 24 hours to determine the MTD of Blank-M.

In the second experiment, the bioactivities of SeNPs-M were evaluated. Forty-eight male mice were randomly divided into six groups with eight mice in each group. The mice were orally administered saline, sodium selenite, Blank-M and SeNPs-M, respectively, at the doses shown in Table 2 with the frequency of once per 2 days. After seven consecutive Se treatment cycles, the mice were fasted overnight and then were sacrificed to obtain their blood and livers. Se in the blood or liver was determined by ICP-MS assay. ${ }^{34}$ Moreover, liver samples were homogenized in ice-cold saline and centrifuged at $12,000 \times \mathrm{g}$ at $4^{\circ} \mathrm{C}$ for 15 minutes. The resulting supernatants and the plasma samples were used to determine the levels of TBARS, GSH, CAT, SOD, GSH-Px and total protein, following the instructions of commercial kits.

\section{Statistical analysis}

In all the experiments, data were presented as mean \pm SD. The difference between two groups was analyzed by Student's $t$-test, while the difference between three or more groups was analyzed by one-way analysis of variance multiple comparisons, involving the utilization of SPSS software program (version 17.0 for Windows). A $P$-value of $<0.05$ was considered statistically significant.

\section{Results and discussion Morphology and formation of CTS-SeNPs}

Many methods were applied to prepare elemental Se. Thus, Se obtained were of various morphologies, such as amorphous, sphere, wire, rob and tube..$^{15,16,19,24,26,36}$ Herein, aqueous $\mathrm{Se}(\mathrm{IV})$ was chemically reduced by Vc to synthesize SeNPs in the presence of CTS. The initial colloid nucleated and then

Table 2 The retention of Se within ICR mice $(n=8)$

\begin{tabular}{lll}
\hline Group & Plasma Se $(\mu \mathrm{g} / \mathrm{mL})$ & Hepatic Se $(\mu \mathrm{g} / \mathrm{g}$ liver $)$ \\
\hline Control & $0.57 \pm 0.27^{\mathrm{a}}$ & $1.36 \pm 0.09^{\mathrm{a}}$ \\
Blank-M & $0.49 \pm 0.23^{\mathrm{a}}$ & $1.29 \pm 0.15^{\mathrm{a}}$ \\
SeNPs-M $(0.5)^{\wedge}$ & $0.71 \pm 0.23^{\mathrm{b}}$ & $2.18 \pm 0.39^{\mathrm{b}}$ \\
SeNPs-M $(2)^{\wedge}$ & $0.61 \pm 0.16^{\mathrm{a}}$ & $4.12 \pm 1.45^{\mathrm{c}}$ \\
SeNPs-M $(8)^{\wedge}$ & $1.46 \pm 0.47^{\mathrm{c}}$ & $8.35 \pm 1.08^{\mathrm{d}}$ \\
Sodium selenite $(2)^{\wedge}$ & $1.12 \pm 0.26^{\mathrm{d}}$ & $5.49 \pm 1.27^{\mathrm{e}}$ \\
\hline
\end{tabular}

Notes: Data were presented as mean $\pm S D$. ^ The number in brackets refers to the dose of selenite or SeNPs-M, based on Se dose ( $\mathrm{mg} \mathrm{Se} / \mathrm{kg}$ body weight). ${ }^{\mathrm{a}-\mathrm{e}}$ Means within a row with different letters differ significantly $(P<0.05)$.

Abbreviations: ICR, Institute of Cancer Research; Blank-M, blank chitosan microspheres; SeNPs-M, selenium nanoparticles-loaded chitosan microspheres; $\mathrm{SD}$, standard deviation. 
assembled into SeNPs (Scheme 1A). In this process, CTS adhered to Se atoms and controlled the size of their aggregates. Finally, monodispersed and homogeneous spherical CTS-SeNPs were obtained (Figure 1A). The colloid's color was dependent on the concentration of SeNPs (Figure 1A inset). Besides, the size distribution analysis conducted using TEM and DLS calculated the average diameters of CTS-SeNPs to be 36 and $95 \mathrm{~nm}$, respectively (Figure 1B). It suggested that there is an invisible layer covering SeNPs since DLS can only measure hydrodynamic size. ${ }^{31}$

A

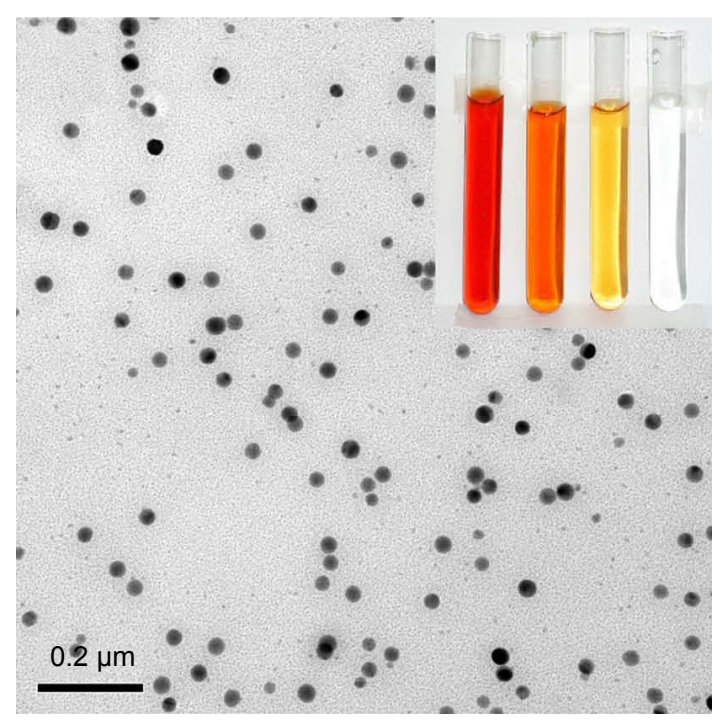

C

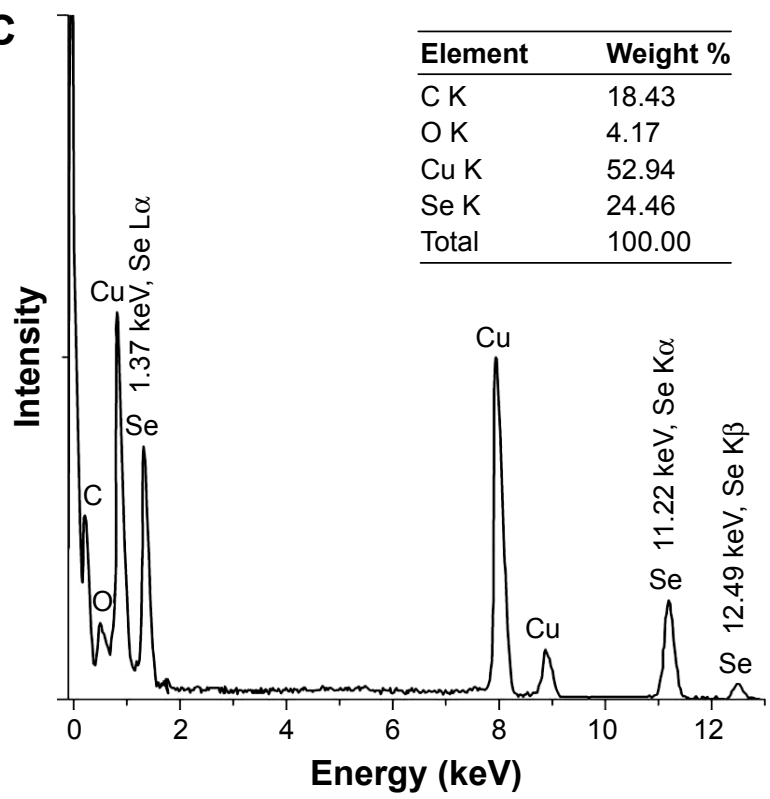

Elemental formation and microstructure of CTS-SeNPs were studied. Clear Se peaks (1.37, 11.22 and $12.49 \mathrm{keV})$ were found in the EDS spectra, confirming the elemental nature of SeNPs (Figure 1C). Besides, the structure of SeNPs synthesized in $0.5 \mathrm{mg} / \mathrm{mL}$ CTS solution was analyzed by high-resolution transmission electron microscopy. As shown in Figure 1D inset, similar crystalline structures with a lattice fringe of $0.35 \mathrm{~nm}$ were observed as compared with the two fringes of 0.149 and $0.31 \mathrm{~nm}$ obtained in the presence of $0.08 \mathrm{mg} / \mathrm{mL}$ CTS and $0.1 \%(\mathrm{w} / \mathrm{w})$ CTS, respectively. ${ }^{15,37}$

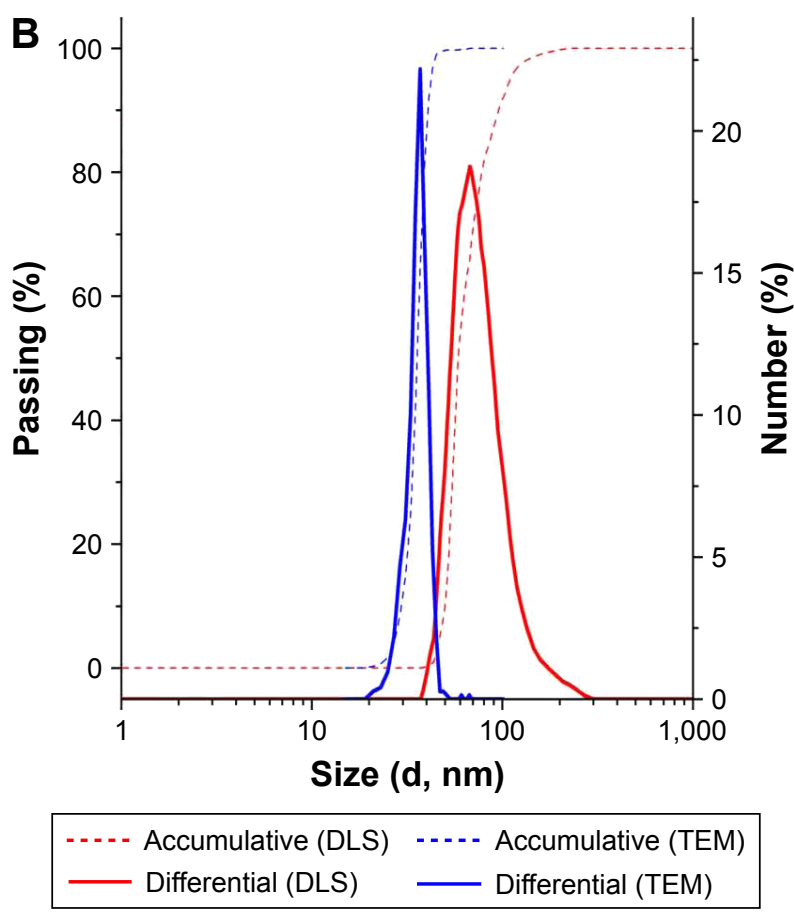

D

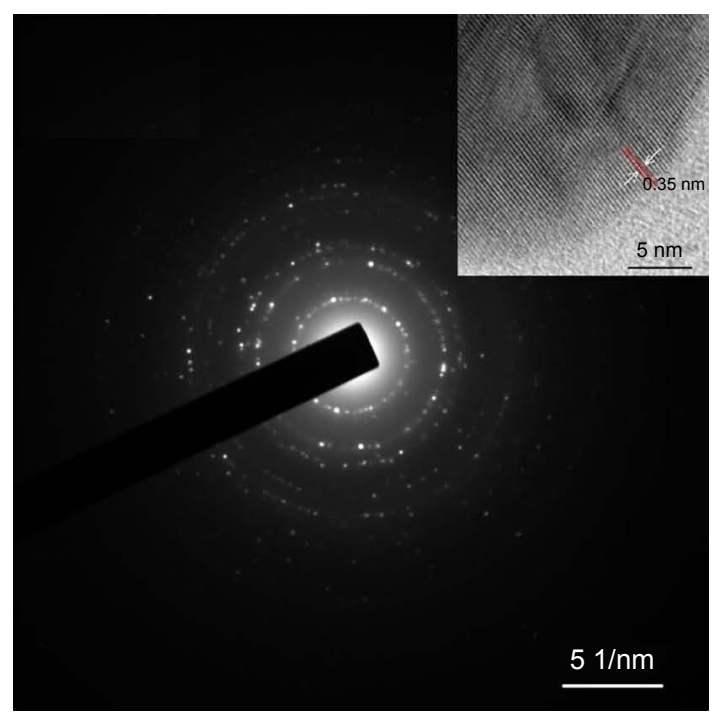

Figure I (Continued) 
E

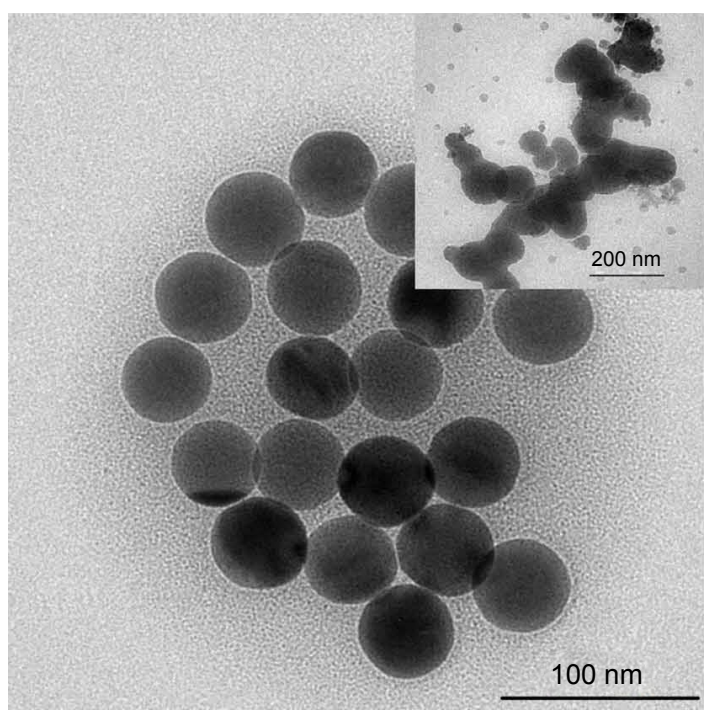

$\mathbf{F}$

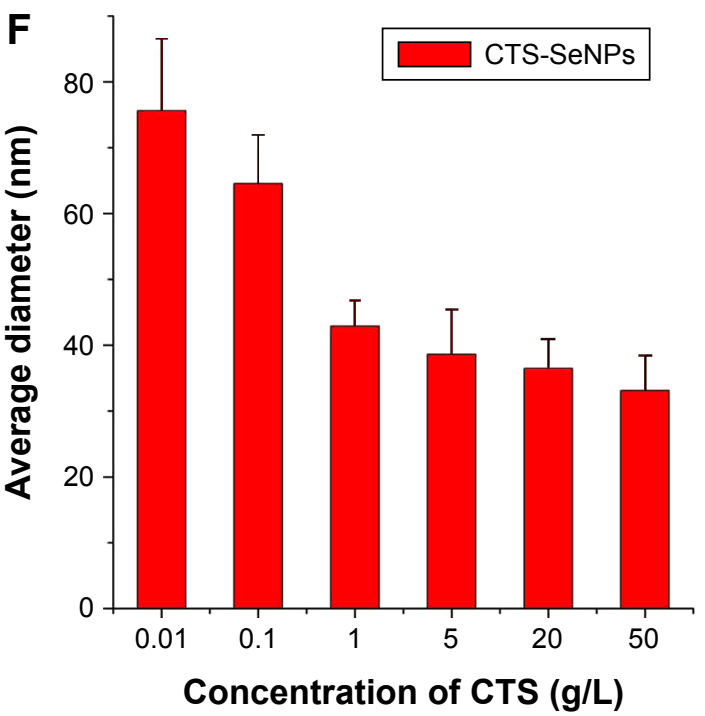

Figure I Morphology and formation of SeNPs freshly synthesized within CTS solution. For synthesis of CTS-SeNPs, CTS and Vc were dissolved in aqueous acetic acid. Then, sodium selenite solution was slowly added to the CTS/Vc solution and stirred to obtain CTS-SeNPs. For the synthesis of bare SeNPs, CTS was replaced with deionized water when preparing CTS-SeNPs. (A) TEM image of CTS-SeNPs and their appearance (inset). (B) The size distribution of CTS-SeNPs measured by TEM or DLS. (C) Typical EDS spectra of CTS-SeNPs and their elemental composition (inset). (D) SAED patterns of CTS-SeNPs and inset for HR-TEM image of individual CTS-SeNPs with a lattice fringe of $0.35 \mathrm{~nm}$. (E) TEM image comparing CTS-SeNPs with bare SeNPs (inset). (F) The influence of CTS concentration on the average sizes of CTS-SeNPs measured by TEM assay ( $n=3)$.

Abbreviations: SeNPs, selenium nanoparticles; CTS, chitosan; Vc, ascorbic acid; TEM, transmission electron microscopy; DLS, dynamic light scattering; EDS, energydispersive X-ray spectroscopy; SAED, selective area electron diffraction; HR-TEM, high-resolution transmission electron microscopy.

Moreover, the selective area electron diffraction patterns demonstrated the orderliness and symmetry of CTS-SeNPs (Figure 1D). It seemed that CTS was helpful to form crystal Se with a nano size. Its concentration seemed to have played an important role in forming various crystalline structures.

The impacts of CTS on the shape and size of SeNPs were also studied. Fresh CTS-SeNPs were monodispersed spherical particles with a high uniformity (Figure 1E), whereas bare SeNPs aggregated to bulks in defect of CTS (Figure 1E inset). A higher concentration of CTS resulted in smaller SeNPs (Figure 1F), similar to the fact that higher concentration of BSA generally leads to SeNPs of a smaller size. ${ }^{6,17}$ Obviously, the morphology of SeNPs could be easily mediated by CTS. A smaller size of CTS-SeNPs, however, might be preferred instead of the bigger ones, since better thermostability, ${ }^{38}$ more powerful antioxidant activities, ${ }^{6}$ and more potent chemopreventive abilities ${ }^{17}$ could be achieved.

\section{Stability of CTS-SeNPs}

Stability is an important factor for nanomaterials. ${ }^{15,16}$ SeNPs decorated by sialic acid ${ }^{21}$ or gum arabic ${ }^{19}$ could be stable for at least 30 days. CTS-SeNPs reported by Yu et a ${ }^{137}$ remained stable for 60 days when stored in $0.08 \mathrm{mg} / \mathrm{mL} \mathrm{CTS} \mathrm{solutions,}$ but the size dramatically increased from 120 to $400 \mathrm{~nm}$ and aggregation began to occur. In this study, bare SeNPs (without CTS) quickly agglomerated in few days, while CTSSeNPs were stable for more than 28 days in $1 \%(w / w)$ CTS solution at $25^{\circ} \mathrm{C}$ (Figure 2A). However, CTS-SeNPs turned to black bulks after 42 days of storage (Figure 2A), accompanied by the enlargement of CTS-SeNPs (Figure 2B). Similar instability of SeNPs within gum arabic solution was reported by Kong et al. ${ }^{19}$ Furthermore, the TEM images of CTSSeNPs were studied. Enlarged size of original CTS-SeNPs was very common at the 28th day (Figure $2 \mathrm{C}$ ), while many aggregates with the size of several micrometers were generated after 42 days of storage (Figure 2D). The aggregates comprising numerous single SeNPs were actually dark bulks that appeared during the long-term preservation. However, the narrow size distribution, highly faceted morphology and uniform edge-to-edge distances between particles induced by heating $40 \mathrm{~nm} \mathrm{SeNPs}{ }^{38}$ were not found among these enlarged SeNPs shown in Figure 2C and D. Perhaps, sharp reconstruction of original SeNPs could not be triggered under such a mild storage condition $\left(25^{\circ} \mathrm{C}\right)$. However, size enlargement and agglomeration of SeNPs seemed to be unavoidable in an aqueous environment.

The zeta potentials of SeNPs were compared for further comprehension of the stability. As presented in Figure 2E, bare SeNPs were slightly negative $(-4.3 \mathrm{mV})$ in the reducing water environment, but the surface decoration by CTS elevated 
A

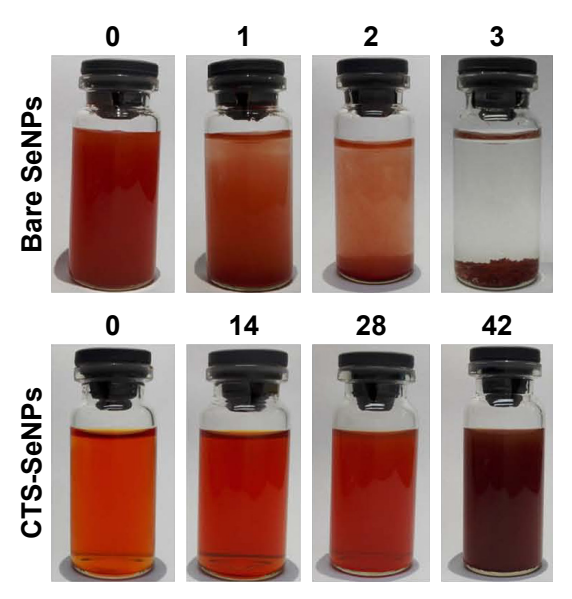

C

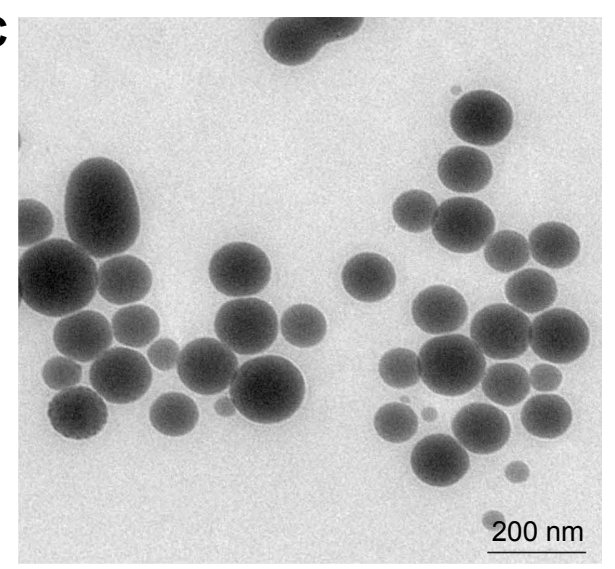

E

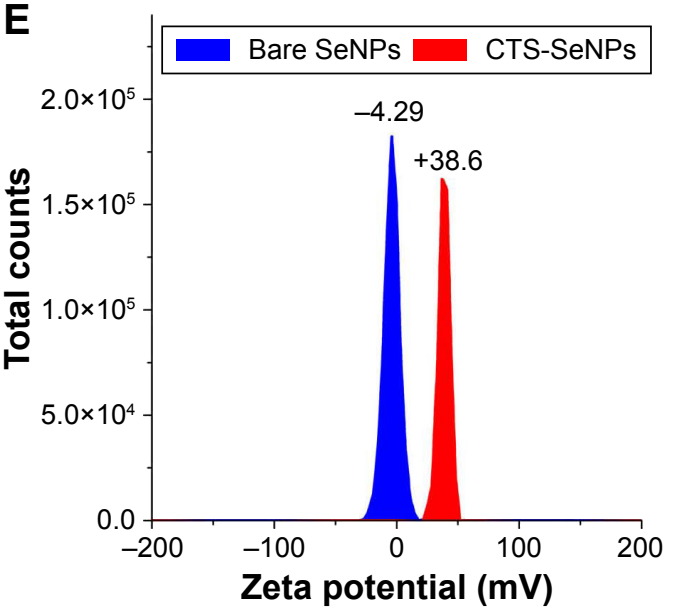

B

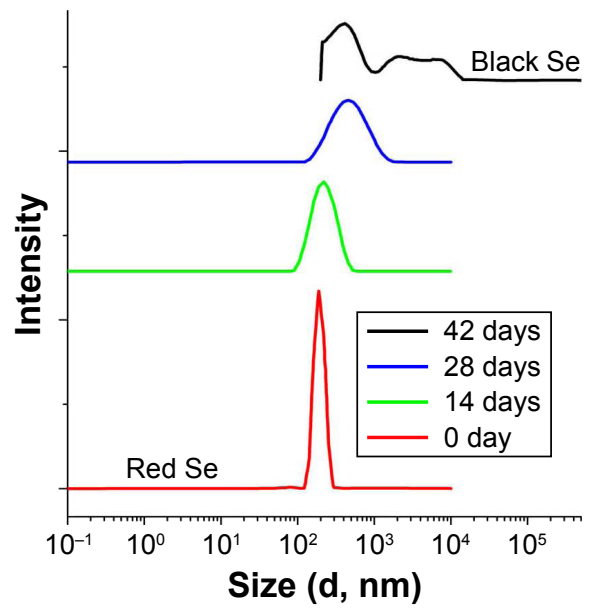

D
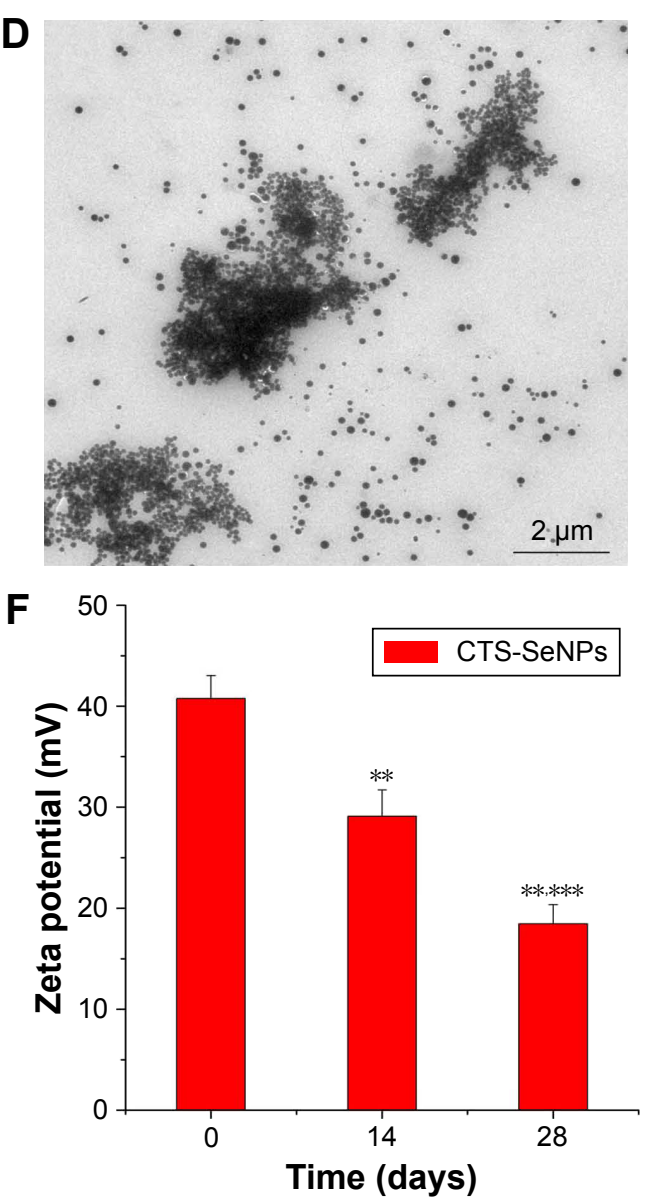

Figure 2 The effects of CTS upon SeNPs. CTS-SeNPs and bare SeNPs were synthesized in the presence and absence of CTS, respectively. (A) Photographs of SeNPs in the presence or absence of CTS during a 42-day storage. Day 0: immediately after sample synthesis day. (B) Size distribution of CTS-SeNPs after 0, I4, 28 and 42 days, respectively. The data of 42 nd day were obtained using LS-POP(6) particle analyzer, while other data within the panel were recorded by VEM3600 particle analyzer. (C) TEM image of CTS-SeNPs after a 28-day storage. (D) TEM image of CTS-SeNPs after a 42-day preservation period. (E) Zeta potentials of new bare SeNPs and fresh CTS-SeNPs recorded by VEM3600 particle analyzer. (F) Zeta potentials of CTS-SeNPs during a 42-day preservation period $(n=3)$. $* * P<0.0 \mathrm{I}$ versus day 0 , and $* * * P<0.0 \mathrm{I}$ versus day I4. Abbreviations: Se, selenium; CTS, chitosan; SeNPs, selenium nanoparticles; TEM, transmission electron microscopy.

the zeta potential of SeNPs to be $+38.6 \mathrm{mV}$, probably due to the positively charged $-\mathrm{NH}_{3}^{+}$groups from CTS. ${ }^{15,25,39}$ It was why the fresh CTS-SeNPs were able to remain very stable. However, the zeta potential decreased from $40.8 \mathrm{mV}$ at the initial day to $18.4 \mathrm{mV}$ at the 28th day (Figure 2F), indicating that CTS-SeNPs become more unstable during storage. Similar results were reported by Kong et al ${ }^{19}$ and Zhang et al. ${ }^{15}$ Considering the relationship between nanoparticles' stability and their zeta potential, it was difficult to preserve CTS-SeNPs in an aqueous solution for a longer time. 


\section{Characterization of SeNPs-M}

Bare SeNPs and CTS-SeNPs were unavailable for commercial application in oral administration system since they were not very stable. To address this problem, SeNPs were maintained in solid state. As illustrated in Scheme 1A, CTSSeNPs were spray-dried, and SeNPs were finally embedded into solid SeNPs-M. White Blank-M (without any Se) and red SeNPs-M were obtained, both of which were free-flowing powders. The Se content of SeNPs-M was determined by ICP-MS,$^{34}$ and it could be adjusted by modifying the material ratio. An SeNPs-M sample (29 $\mathrm{g} \mathrm{Se} / \mathrm{kg}$ ) was selected to conduct the rest of the study.

The morphology of SeNPs-M was studied at first. SeNPs-M were a collection of regular spheres with a smooth
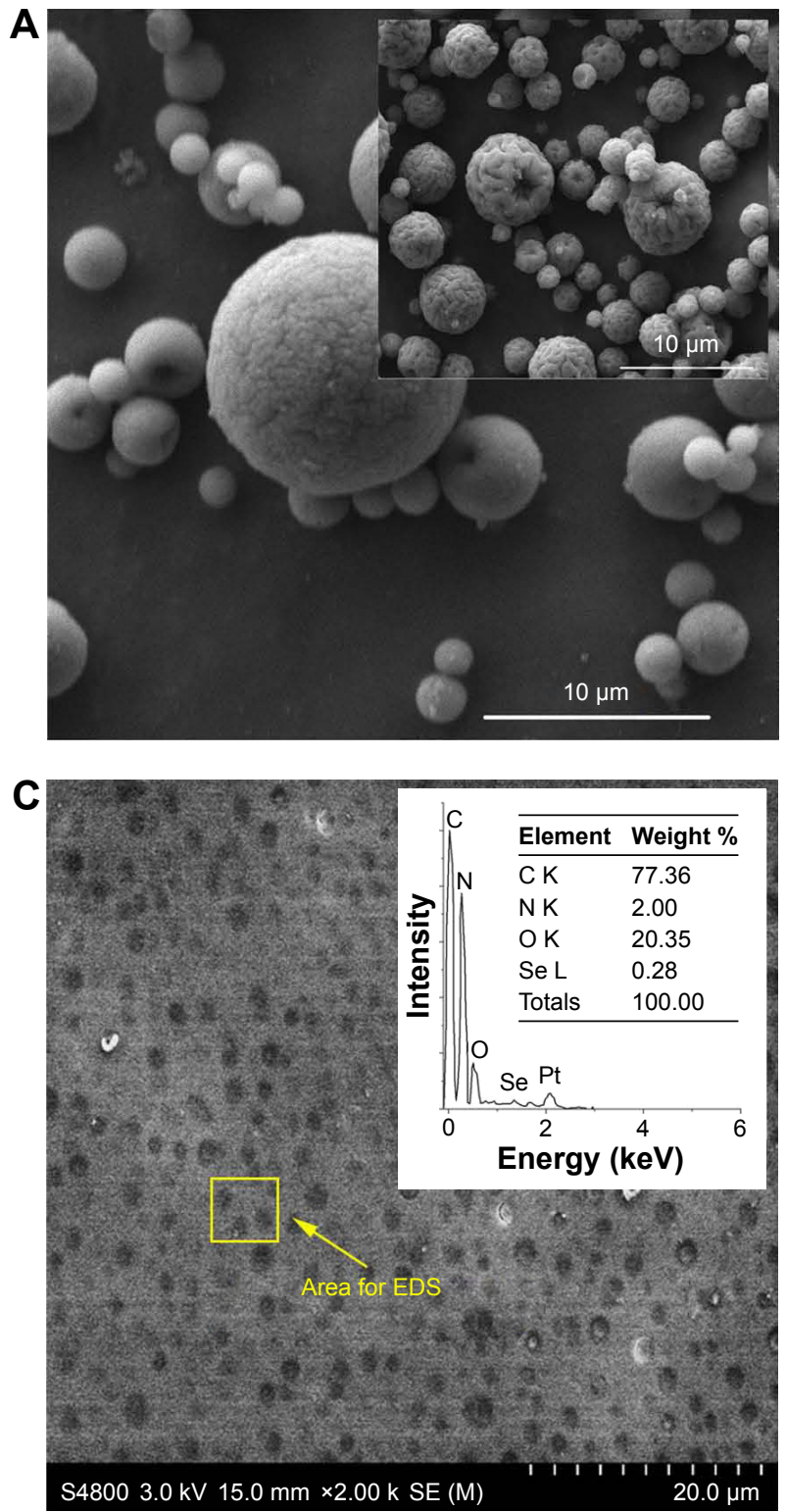

Figure 3 (Continued) surface, while Blank-M were more wrinkled (Figure 3A vs Figure 3A inset). It suggested that SeNPs play an unknown role in forming SeNPs-M. Besides, the average size of SeNPs-M was calculated as $6.24 \mu \mathrm{m}$ in water and $4.21 \mu \mathrm{m}$ in ethanol (Figure 3B). Apparently, SeNPs-M might swell in water. Moreover, EDS analysis was performed on both the surfaces and the cross sections of SeNPs-M to study the Se distribution. As shown in Figure 3C, apparent Se information can hardly be found on the surfaces; however, clear Se signals were observed on the transections (Figure $3 \mathrm{C}$ inset). Thus, there is no doubt that Se was distributed inside SeNPs-M.

Additionally, the spectral features of SeNPs-M were investigated. The FTIR spectra of SeNPs-M were similar to that of Blank-M, without any new chemical structure (Figure 3D).

B

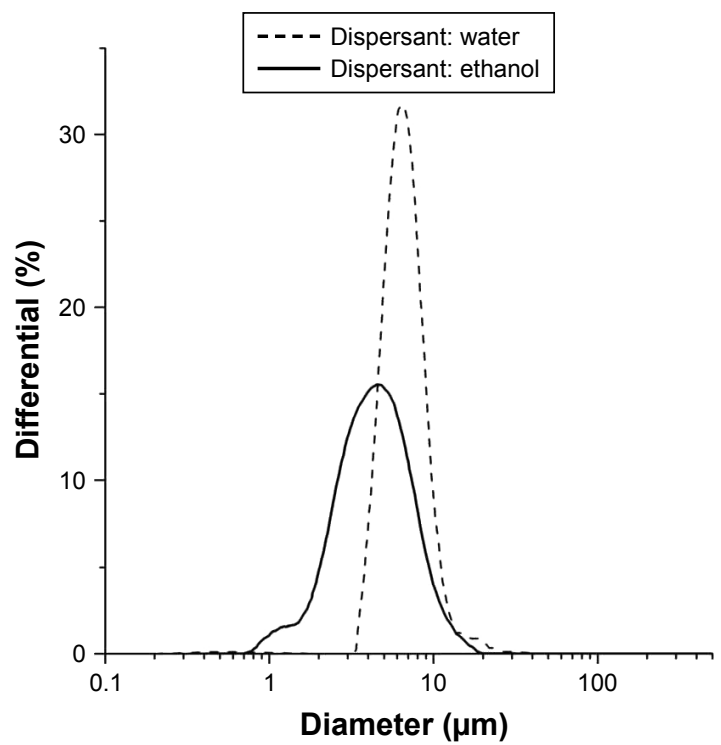

D

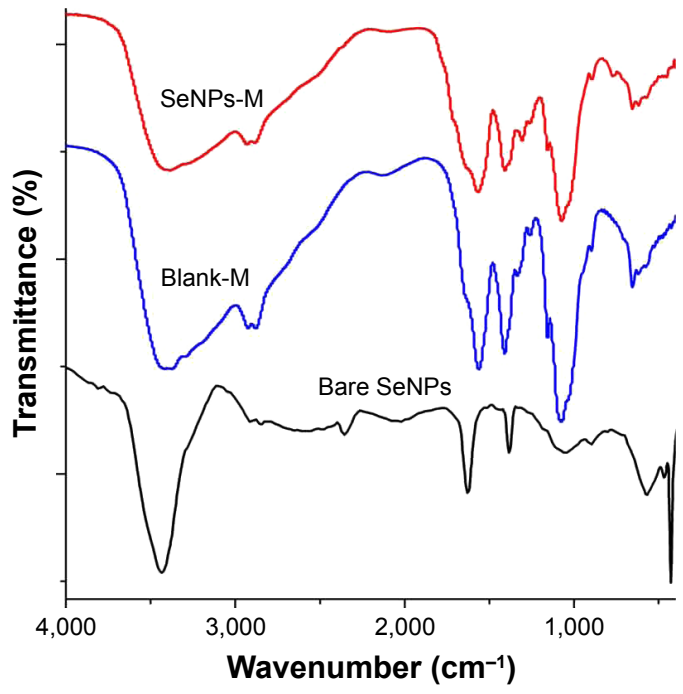



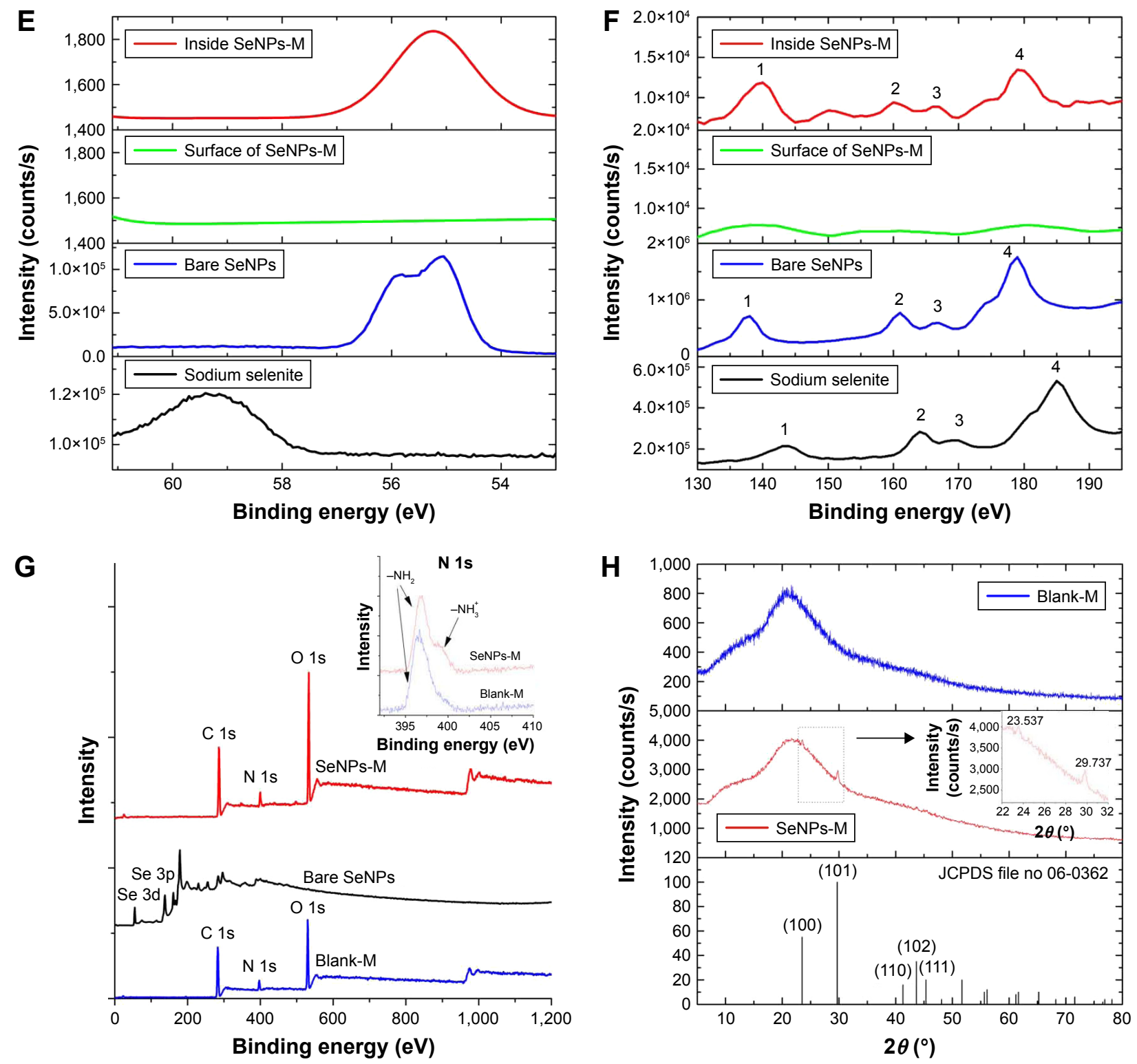

Figure 3 Characterization of SeNPs-M. For the preparation of SeNPs-M, SeNPs were firstly synthesized in the presence of CTS. The mixture of CTS solution and SeNPs was consequently spray-dried to manufacture SeNPs-M. Besides, Blank-M without any Se were obtained by substituting selenite with deionized water when preparing SeNPs-M. (A) SEM image of SeNPs-M and inset for Blank-M. (B) Size distribution of SeNPs-M measured by LS-POP(6) particle analyzer. (C) The SEM image of the cross-sections of CTS-SeNPs and inset for EDS spectra. CTS-SeNPs were frozen and then cut into frozen sections, each $6 \mu \mathrm{m}$ thick, before SEM observation. (D) FTIR spectra of bare SeNPs, Blank-M and SeNPs-M. (E) Se 3d XPS pattern, (F) Se 3p XPS pattern and (G) wide-range XPS pattern of SeNPs-M, recorded by a high-resolution photoelectron spectrograph (Escalab 250Xi) equipped with a monochromatic Al K $\alpha$ X-ray source. Argon ion etching lasting for 60 seconds was applied to expose Se information inside SeNPs-M. For Panel (F), peaks I, 2, 3 and 4 represent the signals of Se LMM2, Se 3p3, Se 3pI and Se LMMI, respectively. (H) XRD patterns of Blank-M and SeNPs-M determined by a X'Pert Pro X-ray diffractometer, using a Cu K $\alpha$ source $(\lambda=0.15406 \mathrm{~nm})$ and the standard XRD spectra of trigonal-phase Se from JCPDS file no 06-0362.

Abbreviations: SeNPs-M, selenium nanoparticles-loaded chitosan microspheres; SeNPs, selenium nanoparticles; CTS, chitosan; Blank-M, blank chitosan microspheres; SEM, scanning electron microscopy; EDS, energy-dispersive X-ray spectroscopy; FTIR, Fourier transform infrared spectroscopy; XPS, X-ray photoelectron spectroscopy; XRD, X-ray diffraction; JCPDS, Joint Committee on Powder Diffraction Standards.

However, significant difference was observed in the XPS patterns of Se $3 \mathrm{~d}$ and $3 \mathrm{p}$ orbitals (Figure $3 \mathrm{E}$ and F). Typical Se $3 \mathrm{~d}$ peaks of $\mathrm{Se}(0)$ and $\mathrm{Se}$ (IV) were detected at 55.3 and $59.5 \mathrm{eV}$, respectively, confirming that the valence state of Se in SeNPs-M was zero, though it needed an Argon ion etching lasting 60 seconds before Se XPS detection to expose the area under the surfaces of the microspheres. Interestingly, the characteristic peaks of $-\mathrm{NH}_{3}{ }^{+}$and $-\mathrm{NH}_{2}$ displayed clear variation between SeNPs-M and Blank-M (Figure 3G). This was consistent with some previous studies reporting that two chemical states of nitrogen could be observed by $\mathrm{N} 1 \mathrm{~s}$ XPS. ${ }^{25}$

Finally, XRD was conducted to analyze the amorphous/ crystalline nature of SeNPs. Typical XRD peaks of crystal Se were found in the XRD patterns of SeNPs-M, while Blank-M were amorphous (Figure 3H). These peaks were 
in accordance with the trigonal phase of Se having lattice constants $a=4.366 \AA, b=4.366 \AA$ and $c=4.954 \AA$, which corresponded to the reported value (JCPDS File No 06-0362). Similar XRD patterns had been found by Sharma et $\mathrm{al}^{31}$ when using dried Vitis vinifera (raisin) to prepare SeNPs, whereas different XRD patterns of SeNPs mediated by 3 or $200 \mathrm{kDa}$ CTS had been reported by Zhang et al. ${ }^{15}$ This suggested that manufacturing condition may greatly affect the crystalline feature of SeNPs.

Based on the characteristics of SeNPs-M, nano-crystal SeNPs were successfully embedded into solid CTS microspheres by spray-drying, generating globular SeNPs-M, which might guarantee the physical isolation of each SeNP (shown in Scheme 1B).

\section{Acute toxicity}

In the acute lethal test, SeNPs-M and sodium selenite at increasing doses (1.78-fold and 1.86-fold, respectively) were administered by single intragastric administration, and mortality were recorded over 14 days. The results presented in Table 1 illustrated that selenite at a dose of $11.0 \mathrm{mg} \mathrm{Se} / \mathrm{kg}$ bw killed all the mice. However, SeNPs-M did not cause any mortality at a dose of $14.6 \mathrm{mg} \mathrm{Se} / \mathrm{kg}$ bw. The $\mathrm{LD}_{50}$ of selenite and SeNPs-M was 3.4 and $62.3 \mathrm{mg} \mathrm{Se} / \mathrm{kg}$ bw, respectively, indicating that the acute toxicity of SeNPs-M was only 1/18 of that of selenite based on Se dose. Considering the safety of Blank-M with an MTD exceeding $15 \mathrm{~g} / \mathrm{kg}$ bw (data not shown), it was not difficult to deduce that it was SeNPs within the SeNPs-M that were responsible for the acute toxicity. This was consistent with some previous studies performed on mice and rat. ${ }^{40-42}$ Remarkably, SeNPs in the form of SeNPs-M were much safer than selenite.

CTS might be superior to BSA ${ }^{40,41}$ in terms of the safety of SeNPs (18-fold vs sevenfold as compared to selenite). In addition to the different species of experiment animals, the ability to release SeNPs might account for the difference between these two forms of SeNPs. As a hydrosoluble protein, BSA could be easily dissolved and enzymolysized in the digestive tract of animals; ${ }^{43}$ thus, the SeNPs might be released quickly, inducing the acute toxicity. However, the release of SeNPs might be retarded by the absorption characteristics of CTS towards many materials ${ }^{32}$ and the deficiency of the enzymes to deal with CTS in some species of animals and human beings. ${ }^{32}$

\section{Growth inhibition}

The bw of mice was recorded and compared during the treatment with saline (as control), sodium selenite, Blank-M and SeNPs-M for 14 consecutive days. It was reported that selenite at the dose of $6 \mathrm{mg} \mathrm{Se} / \mathrm{kg}$ bw resulted in complete growth suppression. ${ }^{3}$ As shown in Figure 4A, however, mice generally kept growing during the administration of
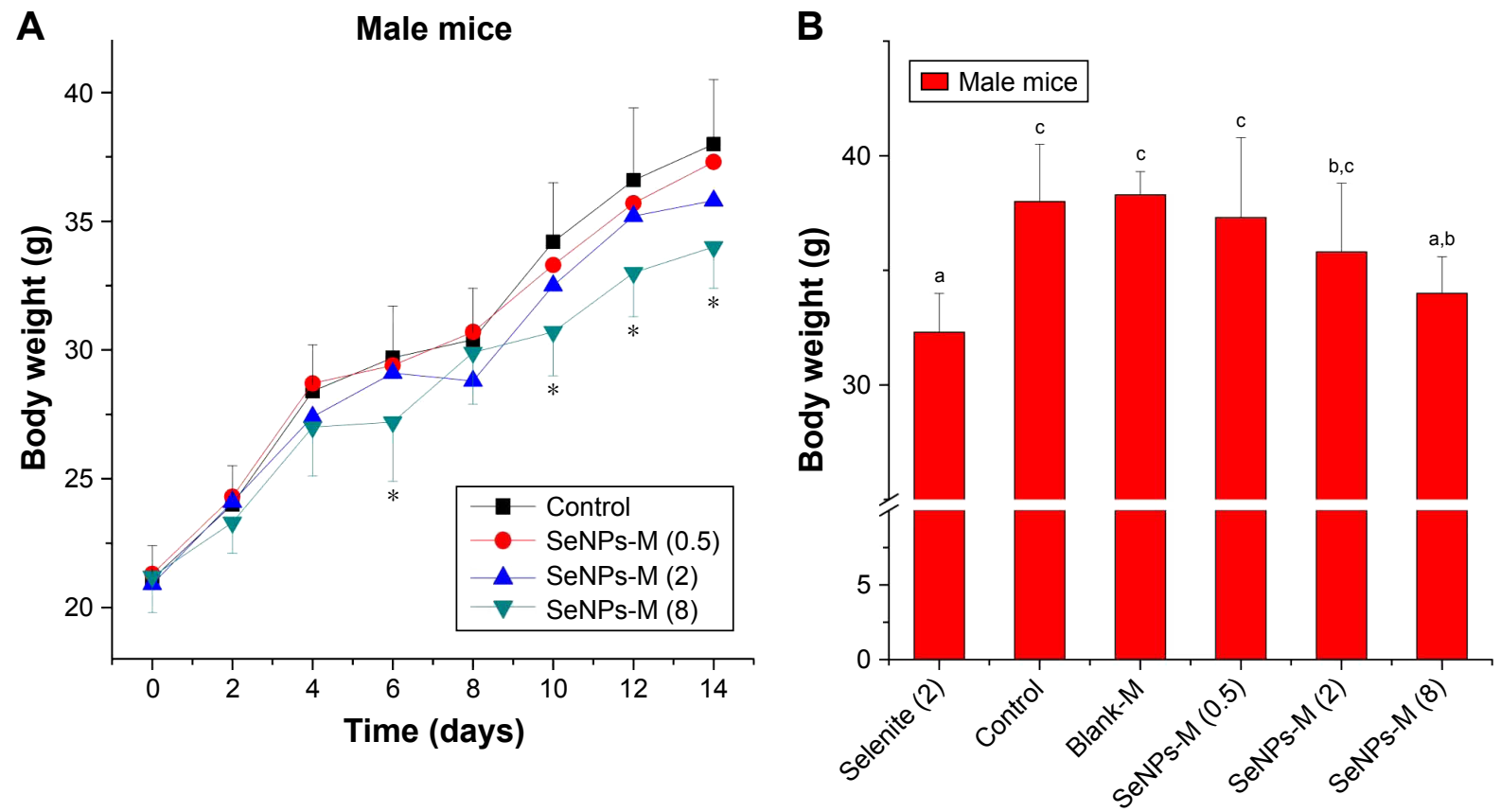

Figure 4 The body weights of male ICR mice during a 14-day treatment period of different selenium source. Se-deficient mice were orally administered saline (Control), sodium selenite (Selenite, $2 \mathrm{mg} \mathrm{Se} / \mathrm{kg}$ bw), blank microspheres (Blank-M) and SeNPs-M once per 2 days for 14 consecutive days. (A) The change of body weight during SeNPs-M treatment $(n=8)$. (B) The impacts of different Se sources on the last body weights $(n=8)$. The number in brackets refers to the dose of selenite or SeNPs-M, based on Se dose (mg Se/kg bw). ${ }^{* P}<0.05$ versus control. a-cMeans within a panel with different letters differ significantly $(P<0.05)$.

Abbreviations: bw, body weight; Blank-M, blank chitosan microspheres; ICR, Institute of Cancer Research; SeNPs-M, selenium nanoparticles-loaded chitosan microspheres. 
SeNPs-M, though this Se form at a high dose of $8 \mathrm{mg} \mathrm{Se} / \mathrm{kg}$ bw might suppress the growth of mice ( $P<0.05$ vs control). After the last treatment, it was found that sodium selenite ( $2 \mathrm{mg} \mathrm{Se} / \mathrm{kg} \mathrm{bw}$ ) significantly inhibited the growth of mice (Figure 4B). It induced more growth inhibition than SeNPs-M at the same Se dose. No statistical significance $(P>0.05)$ could be found between SeNPs ( $2 \mathrm{mg} \mathrm{Se} / \mathrm{kg} \mathrm{bw}$ ) and control. Considering the safety of Blank-M shown in Figure 4B, it was clear that (1) SeNPs in SeNPs-M were responsible for the growth inhibition of mice and (2) that SeNPs-M ( $\leq 2 \mathrm{mg} \mathrm{Se} /$ $\mathrm{kg} \mathrm{bw})$ were safe while selenite at the same dose was toxic.

\section{Se retention}

In order to investigate the Se distribution within the body of mice, the Se contents of the blood and liver were determined. As shown in Table 2, it was evident that (1) SeNPs in SeNPs-M contributed to the Se retention, (2) Se retention occurred in a dose-dependent manner, and (3) Se retention of SeNPs-M was weaker than that of sodium selenite. The last result was different from some reports ${ }^{5,44}$ reporting the greater Se retention of nano-elemental Se (called SeNPs in the present study) over selenite in broiler chickens and male goats, respectively. It implied that the Se retention in animals is complex and is affected by a variety of animal species. Possibly weaker accumulation of Se could partly explain the low toxicity of SeNPs-M compared with selenite according to Wang et al. ${ }^{4}$ Oral administration of SeNPs-M could be an effective way to supply Se.

\section{Biomarkers}

The levels of GSH, TBARS (MDA equivalent), GSH-Px, SOD and CAT were measured to evaluate the antioxidant activities of SeNPs-M. As shown in Table 3, sodium selenite ( $2 \mathrm{mg} \mathrm{Se} / \mathrm{kg}$ bw) increased TBARS content and decreased GSH content vs control $(P<0.05)$. Compared with selenite, however, SeNPs-M at the same Se dose not just reduced TBARS levels but elevated GSH levels. This was consistent with some previous studies, ${ }^{3-5}$ which had confirmed the advantages of SeNPs over selenite. In particular, SeNPs-M significantly enhanced plasma or hepatic GSH-Px activity in a dose-dependent manner, resulting in some twofold increase of GSH-Px activities in Se-deficient mice as compared with control. Based on the data in Table 3, SeNPs-M and selenite had a similar efficacy in increasing GSH-Px activity in the blood and liver of mice. Similar results had been observed by Zhang et $\mathrm{al}^{3,45}$ and by Shi et al, ${ }^{5}$ using mice and goats as the model animal to study nano-elemental Se (SeNPs) controlled by BSA, respectively. Probably, similar GSH-Px activity could be achieved if the amount of Se was equal, no matter whether the SeNPs form was decorated by CTS or BSA. Nevertheless, GSH-Px activity could be saturated at nutritional levels, and further supplementation with supranutritional levels of Se did not further increase its activity. ${ }^{17}$ It could explain why increasing the supplementation of SeNPs-M did not necessarily result in further increase of GSH-Px (Table 3). With respect to other enzymes, selenite (2 $\mathrm{mg} \mathrm{Se} / \mathrm{kg}$ bw) had a little effect on SOD and CAT, but SeNPs-M were helpful in increasing the activities of SOD and CAT even at a low dose of $0.5 \mathrm{mg} \mathrm{Se} / \mathrm{kg}$ bw. More enzymatic activities could be achieved by SeNPs-M vs selenite. In short, SeNPs-M outweighed selenite in terms of antioxidant activities.

\section{Conclusion}

In this study, we introduced a simple way to synthesize and preserve SeNPs. Crystal SeNP spheres were manufactured in the presence of CTS and then were embedded into CTS microspheres by using spray-drying method, giving birth to SeNPs-M. With an $\mathrm{LD}_{50}$ of around 18-fold of that of selenite, SeNPs-M were much safer but had an equal efficacy in increasing GSH-Px activity in vivo when compared with

Table 3 Effects of different Se sources upon antioxidant activities within ICR mice $(n=8)$

\begin{tabular}{|c|c|c|c|c|c|c|c|c|c|c|}
\hline \multirow[t]{2}{*}{ Group } & \multicolumn{5}{|l|}{ Blood } & \multicolumn{5}{|l|}{ Liver } \\
\hline & $\begin{array}{l}\text { GSH } \\
\text { (mg/L) }\end{array}$ & $\begin{array}{l}\text { TBARS } \\
(\mathrm{nmol} / \mathrm{L})\end{array}$ & $\begin{array}{l}\text { GSH-Px } \\
\text { (U/mL) }\end{array}$ & $\begin{array}{l}\text { SOD } \\
(U / m L)\end{array}$ & $\begin{array}{l}\text { CAT } \\
(\mathrm{U} / \mathrm{mL})\end{array}$ & $\begin{array}{l}\text { GSH } \\
\text { (nmol/mg } \\
\text { protein) }\end{array}$ & $\begin{array}{l}\text { TBARS } \\
\text { (nmol/mg } \\
\text { protein) }\end{array}$ & $\begin{array}{l}\text { GSH-Px } \\
\text { (U/mg } \\
\text { protein) }\end{array}$ & $\begin{array}{l}\text { SOD } \\
\text { (U/mg } \\
\text { protein) }\end{array}$ & $\begin{array}{l}\text { CAT } \\
\text { (U/mg } \\
\text { protein) }\end{array}$ \\
\hline Control & $11.20 \pm 1.58^{\mathrm{a}, \mathrm{b}}$ & $0.49 \pm 0.08^{a}$ & $20.4 \pm 1.0^{a}$ & $73.0 \pm 4.4^{\mathrm{a}}$ & $17.4 \pm 1.6^{\mathrm{a}}$ & $4.94 \pm I .45^{\mathrm{a}}$ & $4.69 \pm 1.09^{a}$ & $381 \pm 72^{\mathrm{a}}$ & $978 \pm 32^{\mathrm{a}}$ & $33.2 \pm 2.0^{\mathrm{a}, \mathrm{b}}$ \\
\hline Blank-M & $12.95 \pm 2.57^{b}$ & $0.46 \pm 0.07^{a}$ & $20.5 \pm 1.3^{\mathrm{a}}$ & $75.7 \pm 5.9^{\mathrm{a}, \mathrm{b}}$ & $18.7 \pm 2.2^{\mathrm{a}}$ & $4.20 \pm 0.6 \mathrm{I}^{\mathrm{a}}$ & $4.49 \pm 0.93^{a}$ & $406 \pm 27^{a}$ & $1,020 \pm 103^{a}$ & $33.5 \pm 3.0^{\mathrm{a}, \mathrm{b}}$ \\
\hline $\operatorname{SeNPs}(0.5)^{\wedge}$ & $11.85 \pm 3.10^{\mathrm{a}, \mathrm{b}}$ & $0.43 \pm 0.12^{\mathrm{a}}$ & $35.1 \pm 3.6^{b}$ & $83.7 \pm 3.0^{\mathrm{c}, \mathrm{d}}$ & $21.2 \pm 0.9 c$ & $2.77 \pm 0.69^{b}$ & $5.05 \pm 1.89^{a}$ & $703 \pm 97^{b}$ & $1,160 \pm 96^{b}$ & $41.7 \pm 6.7^{c}$ \\
\hline $\operatorname{SeNPs}(2)^{\wedge}$ & $17.99 \pm 4.82^{c}$ & $0.44 \pm 0.08^{\mathrm{a}}$ & $39.6 \pm 2.2^{c}$ & $85.5 \pm 4.3^{d}$ & $19.2 \pm 1.2^{\mathrm{a}, \mathrm{b}}$ & $2.78 \pm 1.10^{b}$ & $5.65 \pm 1.79^{a}$ & $885 \pm 67^{c}$ & $\mathrm{I}, 065 \pm 53^{\mathrm{a}, \mathrm{b}}$ & $37.6 \pm 2.3^{\mathrm{b}, \mathrm{c}}$ \\
\hline SeNPs $(8)^{\wedge}$ & $13.99 \pm 3.26^{\mathrm{b}}$ & $0.51 \pm 0.14^{\mathrm{a}}$ & $40.7 \pm 1.6^{c}$ & $70.5 \pm 3.4^{\mathrm{a}}$ & $20.7 \pm 1.5^{\mathrm{b}, \mathrm{c}}$ & $2.38 \pm 0.38^{b}$ & $5.59 \pm 1.32^{\mathrm{a}}$ & $855 \pm 101^{c}$ & $992 \pm 53^{a}$ & $39.5 \pm 5.9^{c}$ \\
\hline Sodium selenite $(2)^{\wedge}$ & $8.30 \pm 2.77^{\mathrm{a}}$ & $0.94 \pm 0.27^{b}$ & $41.3 \pm 2.7^{c}$ & $79.0 \pm 3.8^{b, c}$ & $18.0 \pm 1.6^{\mathrm{a}}$ & $2.76 \pm 0.75^{b}$ & $8.6 \mathrm{I} \pm 1.78^{\mathrm{b}}$ & $847 \pm 62^{c}$ & $\mathrm{I}, 053 \pm \mathrm{I} \mathrm{I}^{\mathrm{a}}$ & $29.3 \pm 3.0^{\mathrm{a}}$ \\
\hline
\end{tabular}

Notes: Data were presented as mean \pm SD. ${ }^{\wedge}$ The number in brackets refers to the dose of selenite or SeNPs-M, based on Se dose (mg Se/kg body weight). ${ }^{\mathrm{a}-\mathrm{d} M e a n s}$ within a row with different letters differ significantly $(P<0.05)$.

Abbreviations: ICR, Institute of Cancer Research; GSH, glutathione; TBARS, thiobarbituric acid-reactive substances; GSH-Px, glutathione peroxidase; SOD, superoxide dismutase; CAT, catalase; Blank-M, blank chitosan microspheres; SeNPs-M, selenium nanoparticles-loaded chitosan microspheres. 
selenite. At the same time, levels of intracorporal Se, GSH, SOD and CAT were enhanced by SeNPs-M, while lower level of TBARS (MDA equivalent) was achieved. In summary, this CTS microspheres design of SeNPs opens a new path for oral delivery of Se with a higher efficacy and better biosafety. SeNPs-M can be a candidate Se source worthy of further development for nutrient supplement.

\section{Abbreviations}

Blank-M, blank chitosan microspheres; BSA, bovine serum albumin; bw, body weight; CAT, catalase; CTS, chitosan; DLS, dynamic light scattering; EDS, energy-dispersive X-ray spectroscopy; FTIR, Fourier transform infrared spectroscopy; GSH, glutathione; GSH-Px, glutathione peroxidase; ICR, Institute of Cancer Research; ICP-MS, inductively coupled plasma mass spectrometry; MDA, malondialdehyde; MTD, maximum tolerated dose; SEM, scanning electron microscopy; Se, selenium; SeNPs, selenium nanoparticles; SeNPs-M, selenium nanoparticles-loaded chitosan microspheres; SOD, superoxide dismutase; TBARS, thiobarbituric acid-reactive substances; TEM, transmission electron microscopy; Vc, ascorbic acid; XPS, X-ray photoelectron spectroscopy; XRD, X-ray diffraction.

\section{Acknowledgments}

This work was supported by grants from Scientific and Technological Projects of Fujian Province, People's Republic of China (No 2016N0018), the Scientific Research Foundation of Third Institute of Oceanography, State Oceanic Administration, People's Republic of China (No 2014010), the Science \& Technology Major Projects of Fujian province (No 2014NZ0001) and the Co-sponsored Project by Xiamen Oceanic Research and Development Institute. The authors also thank the support from Southern Ocean Research Center Project of Xiamen (No 13GYY001NF05) and Fujian Collaborative Innovation Center for Exploitation and Utilization of Marine Biological Resources, Third Institute of Oceanography, State Oceanic Administration, Xiamen, Fujian, People's Republic of China.

\section{Disclosure}

The authors report no conflicts of interest in this work.

\section{References}

1. Navarro-Alarcon M, Cabrera-Vique C. Selenium in food and the human body: a review. Sci Total Environ. 2008;400(1-3):115-141.

2. Zhang J, Spallholz JE. Toxicity of selenium compounds and nano-selenium particles. In: Casciano DA, Sahu SC, editors. General, Applied and Systems Toxicology. Hoboken, NJ: John Wiley and Sons; 2011:1-15.
3. Zhang J, Wang H, Yan X, Zhang L. Comparison of short-term toxicity between Nano-Se and selenite in mice. Life Sci. 2005;76(10): 1099-1109.

4. Wang $\mathrm{H}$, Zhang J, Yu H. Elemental selenium at nano size possesses lower toxicity without compromising the fundamental effect on selenoenzymes: comparison with selenomethionine in mice. Free Radic Biol Med. 2007;42(10):1524-1533.

5. Shi L, Xun W, Yue W, et al. Effect of sodium selenite, Se-yeast and nano-elemental selenium on growth performance, Se concentration and antioxidant status in growing male goats. Small Ruminant Res. 2011;96(1):49-52.

6. Huang B, Zhang J, Hou J, Chen C. Free radical scavenging efficiency of Nano-Se in vitro. Free Radic Biol Med. 2003;35(7):805-813.

7. Zhang J, Wang X, Xu T. Elemental selenium at nano size (Nano-Se) as a potential chemopreventive agent with reduced risk of selenium toxicity: comparison with se-methylselenocysteine in mice. Toxicol Sci. 2008;101(1):22-31.

8. Tran PA, Webster TJ. Selenium nanoparticles inhibit Staphylococcus aureus growth. Int J Nanomedicine. 2011;6:1553-1558.

9. Chen T, Wong YS, Zheng W, Bai Y, Huang L. Selenium nanoparticles fabricated in Undaria pinnatifida polysaccharide solutions induce mitochondria-mediated apoptosis in A375 human melanoma cells. Colloids Surf B Biointerfaces. 2008;67(1):26-31.

10. Ramamurthy $\mathrm{CH}$, Sampath KS, Arunkumar P, et al. Green synthesis and characterization of selenium nanoparticles and its augmented cytotoxicity with doxorubicin on cancer cells. Bioprocess Biosyst Eng. 2013; 36(8):1131-1139.

11. Yazdi MH, Mahdavi M, Varastehmoradi B, Faramarzi MA, Shahverdi AR. The immunostimulatory effect of biogenic selenium nanoparticles on the 4T1 breast cancer model: an in vivo study. Biol Trace Elem Res. 2012;149(1):22-28.

12. Li Q, Chen T, Yang F, Liu J, Zheng W. Facile and controllable one-step fabrication of selenium nanoparticles assisted by L-cysteine. Mater Lett. 2010;64(5):614-617.

13. Langi B, Shah C, Singh K, Chaskar A, Kumar M, Bajaj PN. Ionic liquidinduced synthesis of selenium nanoparticles. Mater Res Bull. 2010; 45(6):668-671.

14. Dhanjal S, Cameotra SS. Aerobic biogenesis of selenium nanospheres by Bacillus cereus isolated from coalmine soil. Microb Cell Fact. 2010;9:52.

15. Zhang C, Zhai X, Zhao G, Ren F, Leng X. Synthesis, characterization, and controlled release of selenium nanoparticles stabilized by chitosan of different molecular weights. Carbohydr Polym. 2015;134:158-166.

16. Chen H, Shin DW, Nam JG, Kwon KW, Yoo JB. Selenium nanowires and nanotubes synthesized via a facile template-free solution method. Mater Res Bull. 2010;45(6):699-704.

17. Peng D, Zhang J, Liu Q, Taylor EW. Size effect of elemental selenium nanoparticles (Nano-Se) at supranutritional levels on selenium accumulation and glutathione S-transferase activity. J Inorg Biochem. 2007;101(10):1457-1463.

18. Yang F, Tang Q, Zhong X, et al. Surface decoration by Spirulina polysaccharide enhances the cellular uptake and anticancer efficacy of selenium nanoparticles. Int J Nanomedicine. 2012;7:835-844.

19. Kong H, Yang J, Zhang Y, Fang Y, Nishinari K, Phillips GO. Synthesis and antioxidant properties of gum arabic-stabilized selenium nanoparticles. Int J Biol Macromol. 2014;65:155-162.

20. Soumya RS, Vineetha VP, Reshma PL, Raghu KG. Preparation and characterization of selenium incorporated guar gum nanoparticle and its interaction with H9c2 cells. PLoS One. 2013;8(9):e74411.

21. Zheng JS, Zheng SY, Zhang YB, et al. Sialic acid surface decoration enhances cellular uptake and apoptosis-inducing activity of selenium nanoparticles. Colloids Surf B Biointerfaces. 2011;83(1):183-187.

22. Shirazi AN, Tiwari RK, Oh D, et al. Cyclic peptide-selenium nanoparticles as drug transporters. Mol Pharm. 2014;11(10):3631-3641.

23. Xia YY. Synthesis of selenium nanoparticles in the presence of silk fibroin. Mater Lett. 2007;61(21):4321-4324. 
24. Gao X, Zhang J, Zhang L. Hollow sphere selenium nanoparticles: their in-vitro anti hydroxyl radical effect. Adv Mater. 2002;14(4):290-293.

25. Feng Y, Su J, Zhao Z, et al. Differential effects of amino acid surface decoration on the anticancer efficacy of selenium nanoparticles. Dalton Trans. 2014;43(4):1854-1861.

26. Barnaby S, Sarker N, Dowdell A, Bannerjee I. The spontaneous formation of selenium nanoparticles on gallic acid assemblies and their antioxidant properties. Fordham Undergraduate Res J. 2011;1(1):41-46.

27. Pi J, Jin H, Liu R, et al. Pathway of cytotoxicity induced by folic acid modified selenium nanoparticles in MCF-7 cells. Appl Microbiol Biotechnol. 2013;97(3):1051-1062.

28. Wu S, Sun K, Wang X, Wang D, Wan X, Zhang J. Protonation of epigallocatechin-3-gallate (EGCG) results in massive aggregation and reduced oral bioavailability of EGCG-dispersed selenium nanoparticles. J Agric Food Chem. 2013;61(30):7268-7275.

29. Wang H, Wei W, Zhang SY, et al. Melatonin-selenium nanoparticles inhibit oxidative stress and protect against hepatic injury induced by Bacillus Calmette-Guérin/lipopolysaccharide in mice. J Pineal Res. 2005;39(2):156-163.

30. Zhang Y, Li X, Huang Z, Zheng W, Fan C, Chen T. Enhancement of cell permeabilization apoptosis-inducing activity of selenium nanoparticles by ATP surface decoration. Nanomedicine. 2013;9(1):74-84.

31. Sharma G, Sharma AR, Bhavesh R, et al. Biomolecule-mediated synthesis of selenium nanoparticles using dried Vitis vinifera (raisin) extract. Molecules. 2014;19(3):2761-2770.

32. Rinaudo M. Chitin and chitosan: properties and applications. Prog Polym Sci. 2006;31(7):603-632.

33. Huh Y, Cho HJ, Yoon IS, et al. Preparation and evaluation of spray-dried hyaluronic acid microspheres for intranasal delivery of fexofenadine hydrochloride. Eur J Pharm Sci. 2010;40(1):9-15.

34. Dufailly V, Noël L, Guérin T. Determination of chromium, iron and selenium in foodstuffs of animal origin by collision cell technology, inductively coupled plasma mass spectrometry (ICP-MS), after closed vessel microwave digestion. Anal Chim Acta. 2006;565(2):214-221.
35. Bliss CI. The calculation of the dosage-mortality curve. Ann Appl Biol. 1935;22(1):134-167.

36. Gates B, Mayers B, Cattle B, Xia Y. Synthesis and characterization of uniform nanowires of trigonal selenium. Adv Funct Mater. 2002; 12(3):219-227.

37. Yu B, Zhang Y, Zheng W, Fan C, Chen T. Positive surface charge enhances selective cellular uptake and anticancer efficacy of selenium nanoparticles. Inorg Chem. 2012;51(16):8956-8963.

38. Zhang J, Taylor EW, Wan X, Peng D. Impact of heat treatment on size, structure, and bioactivity of elemental selenium nanoparticles. Int $J$ Nanomedicine. 2012;7:815-825.

39. Huang Y, He L, Liu W, et al. Selective cellular uptake and induction of apoptosis of cancer-targeted selenium nanoparticles. Biomaterials. 2013;34(29):7106-7116.

40. Gao X, Zhang J, Zhang L. [Acute toxicity and bioavailability of nano red elemental selenium]. Wei Sheng Yan Jiu. 2000;29(1):57-58. Chinese [with English abstract].

41. Zhang JS, Gao XY, Zhang LD, Bao YP. Biological effects of a nano red elemental selenium. Biofactors. 2001;15(1):27-38.

42. Jia X, Li N, Chen J. A subchronic toxicity study of elemental Nano-Se in Sprague-Dawley rats. Life Sci. 2005;76(17):1989-2003.

43. Madureira AR, Pereira CI, Gomes AMP, Pintado ME, Malcata FX. Bovine whey proteins - overview on their main biological properties. Food Res Int. 2007;40(10):1197-1211.

44. Hu CH, Li YL, Xiong L, Zhang HM, Song J, Xia MS. Comparative effects of nano elemental selenium and sodium selenite on selenium retention in broiler chickens. Anim Feed Sci Technol. 2012;177(3-4): 204-210.

45. Zhang J, Wang H, Bao Y, Zhang L. Nano red elemental selenium has no size effect in the induction of seleno-enzymes in both cultured cells and mice. Life Sci. 2004;75(2):237-244.
International Journal of Nanomedicine

\section{Publish your work in this journal}

The International Journal of Nanomedicine is an international, peerreviewed journal focusing on the application of nanotechnology in diagnostics, therapeutics, and drug delivery systems throughout the biomedical field. This journal is indexed on PubMed Central,

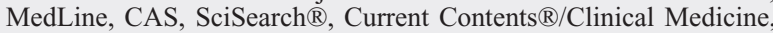

\section{Dovepress}

Journal Citation Reports/Science Edition, EMBase, Scopus and the Elsevier Bibliographic databases. The manuscript management system is completely online and includes a very quick and fair peer-review system, which is all easy to use. Visit http://www.dovepress.com/ testimonials.php to read real quotes from published authors. 